\title{
ADVANCING THE DOCUMENTATION OF BURIED ARCHAEOLOGICAL LANDSCAPES
}

\author{
W. Neubauer ${ }^{1,2}$, M. Doneus ${ }^{2,3,1}$, I. Trinks ${ }^{1}$ \\ ${ }^{1}$ Ludwig Boltzmann Institute for Archaeological Prospection and Virtual Archaeology, Hohe Warte 38, A-1190-Vienna, Austria. \\ ${ }^{2}$ VIAS - Vienna Institute for Archaeological Science, University of Vienna, Franz Klein-Gasse 1/V, A-1190-Vienna, Austria. \\ ${ }^{3}$ UFG - Institute for Prehistoric and Medieval Archaeology, University of Vienna, Franz Klein-Gasse 1/III, A-1190-Vienna, Austria.
}

\section{CIPA, ICOMOS and WG V/2}

KEY WORDS: Archaeology, Aerial Archaeology, LiDAR, Ground Penetrating Radar, magnetometry, hyperspectral imaging spectroscopy

\begin{abstract}
:
The future demands on professional archaeological prospection will be its ability to cover large areas in a time and cost efficient manner with very high spatial resolution and accuracy. The objective of the 2010 in Vienna established Ludwig Boltzmann Institute for Archaeological Prospection and Virtual Archaeology, in collaboration with its nine European partner organisations, is the advancement of the state-of-the-art. This goal will be achieved by focusing on the development of remote sensing, geophysical prospection and virtual reality applications. Main focus will be placed on novel integrated interpretation approaches combining cutting-edge near-surface prospection methods with advanced computer science.
\end{abstract}

\section{INTRODUCTION}

Over the past decades landscape archaeology has increasingly gained importance. Despite a vast variety of approaches, a tacit agreement consists in the fact that landscape archaeologists are investigating beyond the individual site, dealing with space at different scales. This has led many archaeologists, but also preservationists, to enlarge their field of endeavour from individual sites towards entire archaeological landscapes.

In order to be able to protect archaeological landscapes, these have to be identified and documented, which for various reasons presents an archaeological challenge: The massive threat of destruction and deterioration of buried cultural heritage demands for fast, efficient and reliable methods for its identification, documentation and interpretation. At the same time, the European Convention on the Protection of the Archaeological Heritage (Valletta-Convention) states that nondestructive investigation methods should be applied wherever possible (ETS N143, article 3).

Therefore, large-scale applications of non-invasive archaeological prospection methods (e.g. aerial archaeology, airborne laser scanning (ALS) and all kinds of near-surface geophysical prospection) comprise a great potential. These methods offer the most appropriate solution in order to provide both landscape archaeologists and planning authorities with the necessary spatial information at multiple scales, ranging from the archaeological site to a complete archaeological landscape. However, scientific archaeological prospection requires the implementation and adherence to the highest technical standards in regard to instrumentation, spatial sampling intervals, positioning accuracy, data processing and visualization, as well as appropriate novel methodological concepts for the archaeological interpretation of individual sites and archaeological landscapes. This requirement demands coordinated fundamental research aimed at the development and improvement of new ways to acquire the basic data sets, and to extract their archaeologically relevant information by means of well-thought, integrative interpretation tools.

\section{THE LBI INITIATIVE}

The Ludwig Boltzmann Institute for Archaeological Prospection and Virtual Archaeology (LBI ArchPro), founded in April 2010, is focusing on the necessary fundamental and applied research to develop remote sensing, geophysical prospection, Virtual Reality applications and novel integrated interpretation approaches dedicated to landscape archaeology. The LBI ArchPro is based in Vienna, but integrates a Europe-wide partner consortium, representing academic and research institutions, archaeological service providers, and governmental authorities from Austria, Germany, Great Britain, Norway, and Sweden. Its major objectives are

1. The development of novel methods, algorithms and software tools for the processing, digital GIS-based description and three-dimensional visualization of the huge amount of data collected.

2. Sophisticated processing of the airborne and geophysical data for subsequent integrated archaeological interpretation.

3. The development of an integrative GIS-based platform for researchers to manage and to collaborate on the huge and complex datasets covering archaeological landscapes.

4. Among these implementations, Virtual Reality will function as an important interface technology, making data and results graphically accessible to the scientific community and the public.

The research programme is focusing on the following programme lines: Archaeological Remote Sensing, Archaeological Geophysical Prospection and Archaeological Interpretation, Spatial Analysis \& Virtual Archaeology. 


\section{RESEARCH PROGRAMME}

\subsection{Airborne archaeological remote sensing}

3.1.1 Automatized orthorectification of aerial imagery: In order to make use of their archaeological potential, the photographs have to be interpreted and mapped. As a basic requirement, the photographs should be orthorectified at a sufficient accuracy, depending on the scale, defined by the smallest features that will be interpreted. For a highly accurate georeferencing and orthophoto generation from aerial photography, photogrammetrical software and expert experience are necessary (Scollar et al., 1990). Although suitable software is already available at reasonable prices, rectification still is a time consuming and therefore costly process: most time is needed for the identification of appropriate ground control points. Especially in case of large scale projects comprising thousands of aerial photographs, accurate orthorectification will be a crucial factor in terms of time and cost expenditure.

Therefore, one task of the LBI ArchPro is to research and develop tools for semi-automatic orthorectification and georeferencing of aerial photography. This is achieved by the construction of a hand-held calibrated camera-system with attached GPS and low-cost Inertial Measurement Unit (IMU), as well as by the development of software to approximately georeference the oblique images relative to existing orthophotos of the respective area.

The GPS and IMU data will be used as initial input values for the outer orientation of the photograph. Using a Digital Terrain Model (DTM), orthophotos, and the approximate georeferencing information provided by GPS and IMU, the detailed georeferencing of the images and image blocks will be performed by matching of corresponding control points determined in the orthophoto and the oblique photographs. Additionally, it will be investigated whether the latter matching strategy can also be used for georeferencing and proper orthorectification of older aerial imagery and imagery acquired without GPS+IMU data (see Figure 1 for a first attempt).

3.1.2 Full-waveform airborne laser scanning: Due to its ability to measure the ground under a vegetation canopy, ALS has a major impact on the archaeological reconnaissance of vegetated areas. The extension of aerial archaeology with stateof-the-art ALS (Pfeifer and Briese, 2007) and the development of applications of ALS for archaeological prospection is a promising and challenging task investigated by the LBI ArchPro.

The main objective is the development of ALS applications for archaeological prospection. We assume that full-waveform (FWF) ALS systems will show considerable advantages for the generation of DTMs in vegetated areas, as the FWF-parameters might improve classification of ALS data into terrain and offterrain points, resulting in improved DTM quality and a higher potential for the subsequent archaeological interpretation (Doneus et al. 2011). As FWF-ALS displays a great potential, but still is in its infancy (in contrast to conventional ALS sensors FWF-ALS is just available since a few years), several key topics, such as the evaluation of the data acquisition timeframe, and various techniques for advanced classification of the acquired point cloud, as well as visualisation techniques are being investigated (Figure 2). This research is conducted on the basis of repeated test flights using RIEGL LMS-Q680i laser scanners (www.riegl.com).

Other research topics under investigation are the complex interaction of the laser beam with different types of vegetation cover (Doneus and Briese 2010) and the radiometric calibration of ALS-data: in order to enhance the quality of the DTMs and to allow for a reliable interpretation of the acquired data, an indepth understanding of the interaction of the emitted laser beam with the sensed surface is essential. Up to now only the geometric information represented by the ALS point cloud is typically used for archaeological interpretation. Aside from geometrical information ALS additionally provides radiometric information (typically short-wavelength-infrared), which depends on many influencing factors (e.g. flight altitude, laser power, atmospheric conditions) and has to be calibrated in order to allow for a flight independent interpretation of the data. This additionally knowledge gained will help to develop advanced methods for DTM generation based on FWF-information (Lehner and Briese 2010).

3.1.3 Systematic evaluation of airborne imaging spectroscopy (AIS) data for aerial archaeology: Conventional aerial photographic reconnaissance and the interpretation of aerial images depend on a wide range of parameters involved in the formation of visibility marks. Aerial archaeologists conventionally focus their interest on the interaction of visible and near-infrared (NIR) radiation with vegetation. Using analogue film or digital sensors, these visible and the NIR bands of the spectrum can be recorded within up to three bands with bandwidths of roughly $100 \mathrm{~nm}$ (Verhoeven 2008). However, each plant shows a characteristic signature over the entire spectrum depending on its type, environmental conditions and stress due to the archaeological structure underneath. This characteristic spectral "fingerprint" can only be crudely visualized by the three bands of conventional imaging (Figure $3)$.

Using airborne imaging spectroscopy devices, there is a high potential to overcome the limitations of conventional aerial photography and significantly enhance the detection of archaeological structures even undler less favourable conditions. The LBI ArchPro systematically evaluates AIS data for archaeological purposes. Selected sample-regions within case study areas are repeatedly coveredl by AIS sensors together with simultaneous ground-based measurements using a spectrometer for radiometric correction purposes. The combined, GIS-based interpretation of the different data focuses on the evaluation of the most suitable band combinations for archaeological interpretation depending on the mission parameters (sensor type, acquisition date, spectral and geometrical resolution). Data acquisition and systematic evaluation concentrates on selected areas, which are fully covered by geophysical prospection in order to compare the success rate of AIS with an independent control measure.

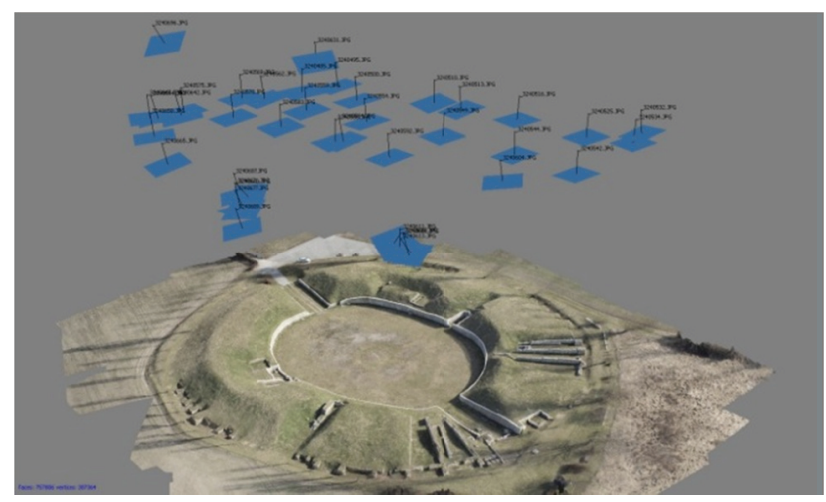

Figure 1. 3D visualization of the Roman civil amphitheatre of Carnuntum (Austria). The camera positions and 3D geometry is extracted fully automatically using computer vision algorithms (Doneus et al. 2012, Fig. 1). 
International Archives of the Photogrammetry, Remote Sensing and Spatial Information Sciences, Volume XXXIX-B5, 2012 XXII ISPRS Congress, 25 August - 01 September 2012, Melbourne, Australia

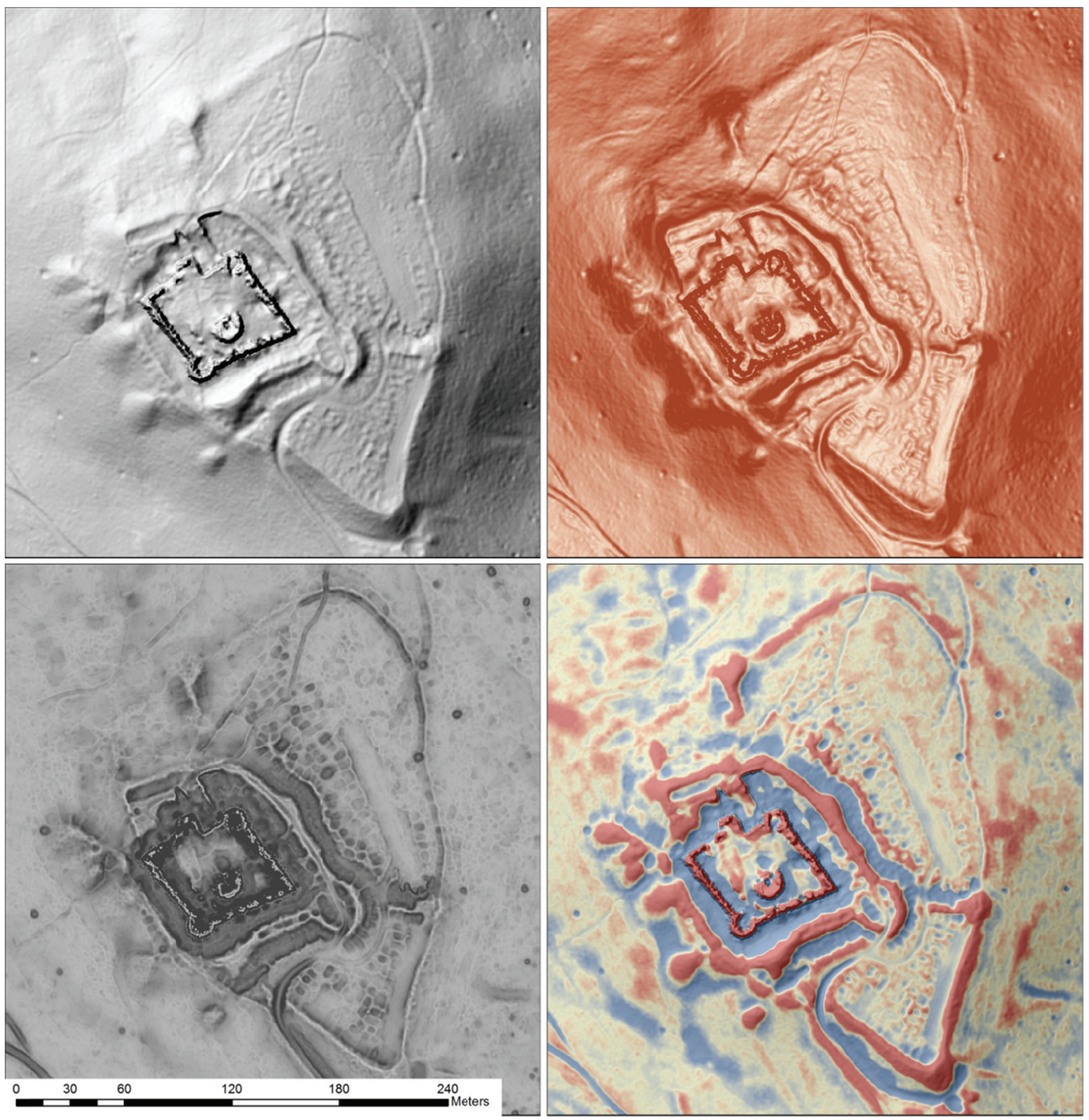

Figure 2. Visualisation of a filtered DTM of a Medieval ruined castle in the case-study area St. Anna. Upper left: hillshade; upper right: combination of hillshade and slope; lower left: positive and negative openness; lower right: local relief model and hillshade.

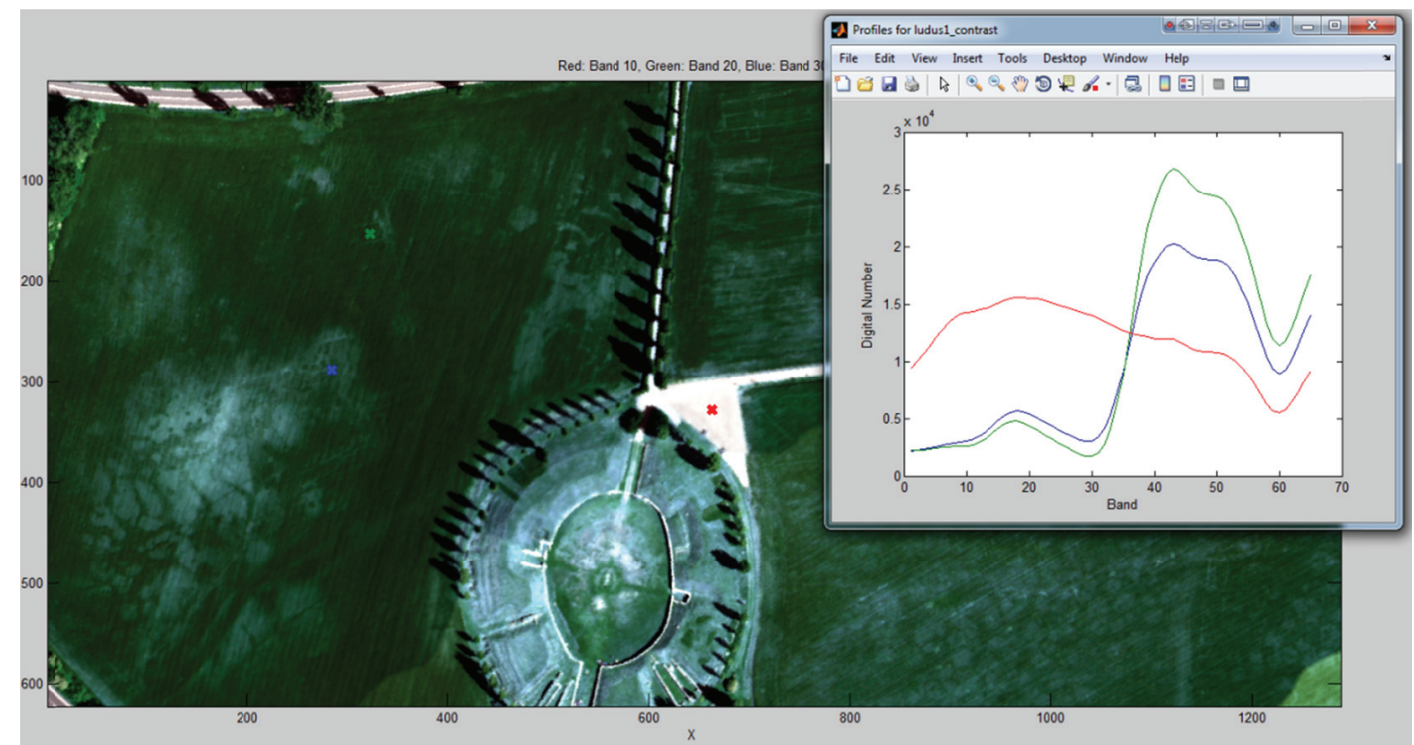

Figure 3. Investigating the spectral profile of cropmarks due to stressed (blue) and unstressed (green) vegetation in the case-study area of Carnuntum. 


\subsection{Efficient geophysical archaeological prospection}

Geophysical archaeological prospection offers efficient and powerful, non-destructive methods for the discovery and detailed mapping of archaeological structures hidden in the shallow subsurface (Linford, 2006; Gaffney and Gater, 2003; Neubauer, 2001b; Scollar et al., 1990). In respect to the LBI ArchPro objective to develop efficient techniques for noninvasive prospection the most promising methods are magnetic survey, resistivity mapping and ground penetrating radar (GPR).

3.2.1 Motorized multisensory measurement devices: In order to enable large-scale near surface geophysical prospection an increase in measurement efficiency is needed. The most important issues regarding professional archaeological prospection are speed, sensitivity and spatial resolution (Becker, 2009). The coverage of considerably larger areas and increased sample densities at constant expenditure of time in the field are today possible by high inherent sample rates of the used instruments and by dramatically increased survey speed offered by motorized multichannel sensor systems and advanced navigation solutions. The use of motorized measurement devices for archaeological prospection implicates several technological and methodological challenges.

For large-scale prospection fluxgate gradiometer (FG) and very sensitive, multisensory Caesium (CS) magnetometer systems (Pico Envirotec) are mounted on purpose-built non-magnetic carts, which are towed by motorized All Terrain Vehicles (ATV) or Quad bikes. The ATVs carry the power supply, the data logging unit and advanced navigation systems. Sensor arrangements with up to 10 Foerster fluxgate probes mounted with $25 \mathrm{~cm}$ cross-line spacing on the trailers, as well as access to more than a dozen CS sensors will permit the setup of several magnetometer arrays for efficient large-scale magnetic surveys (Fig. 4). In case of GPR surveys newly developed multi-channel antenna arrays (MIRA - MALA Geoscience AB) permit considerably increased spatial coverage with simultaneously greatly improved sample spacing of up to $4 \times 8 \mathrm{~cm}$ (Fig. 5), resulting in images of the subsurface of unprecedented resolution and structural clarity (Trinks et al., 2010) .

3.2.2 Automated positioning, survey navigation and topographic data corrections: Exact real time positioning of the motorized multichannel sensor arrays with centimetre accuracy is of paramount importance for data quality and subsequent imaging, analysis and interpretation. The requirements for fast, highly accurate real-time positioning systems and advanced navigation are identical in case of both motorized magnetometer and GPR prospection, permitting the development of a common solution. A promising approach can be realized using real-time kinematic positioning technology based on GPS systems and robotic total-stations with centimetre accuracy (Gaffney, 2008; Leckebusch, 2005). They are crucial for exact data positioning and navigation and permit highly efficient motorized survey systems resulting in considerably increasing efficiency and data quality.

Topographic factors seriously affect data quality during data collection. The local topography and corresponding GPR antenna tilt (Goodman at al. 2006)), in-line as cross-line, have to be taken into account during data processing in order to achieve correct data projection and imaging. Ground and airborne based terrestrial laser-scanning (TLS and ALS) permit the mapping of the micro-topography in very high resolution, allowing for the efficient integration of local topography models into the geophysical data processing and visualization. The mapping of the micro-topography in combination with geophysical survey data will permit for the development, implementation and application of improved data correction algorithms, resulting in considerably increased data and image quality.

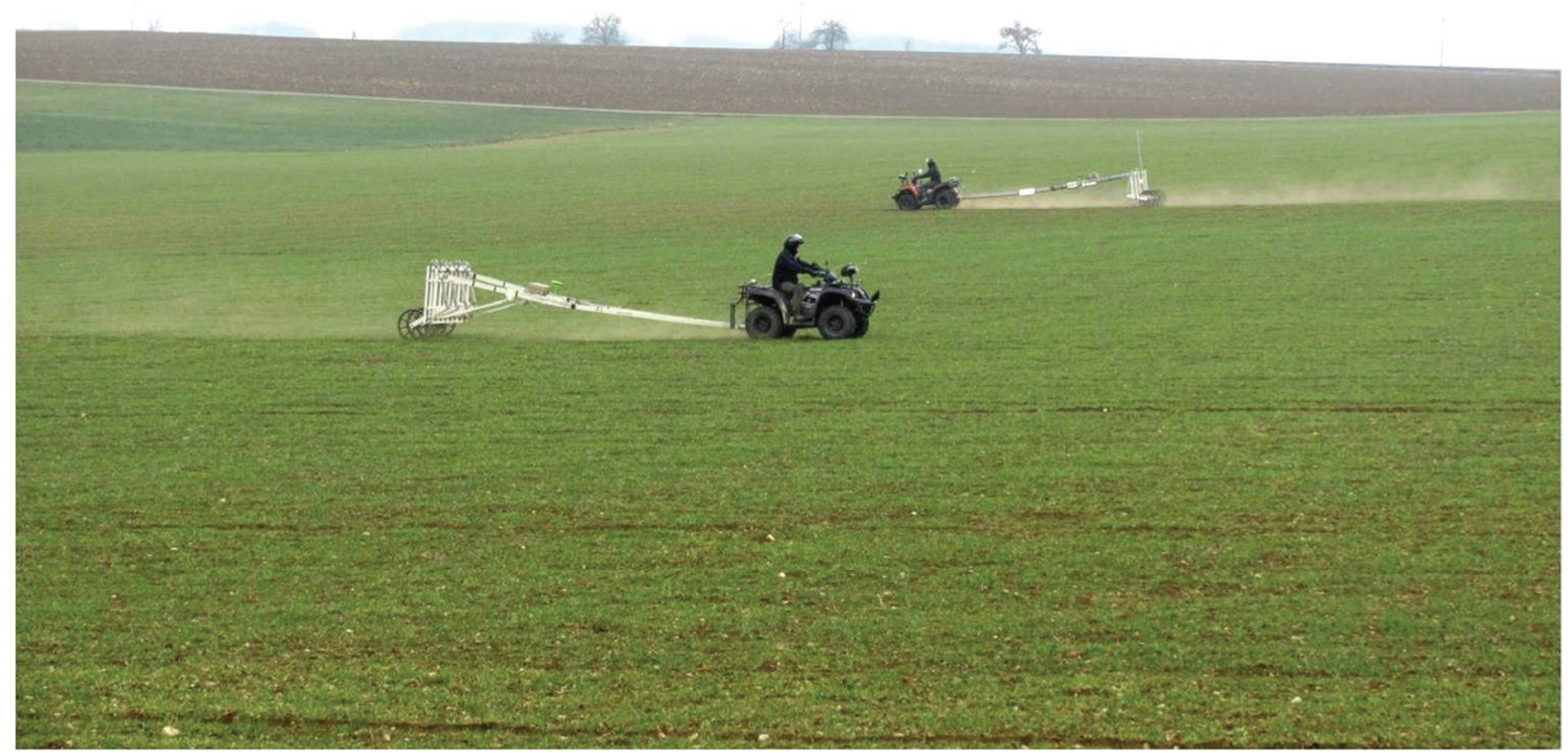

Figure 4. Motorized multichannel Fluxgate gradiometer systems based on 10-channel digitizers, Realtime Kinematic GPS receivers and navigation solutions permit the high-resolution magnetic archaeological prospection of over 15 hectares per day and system. 


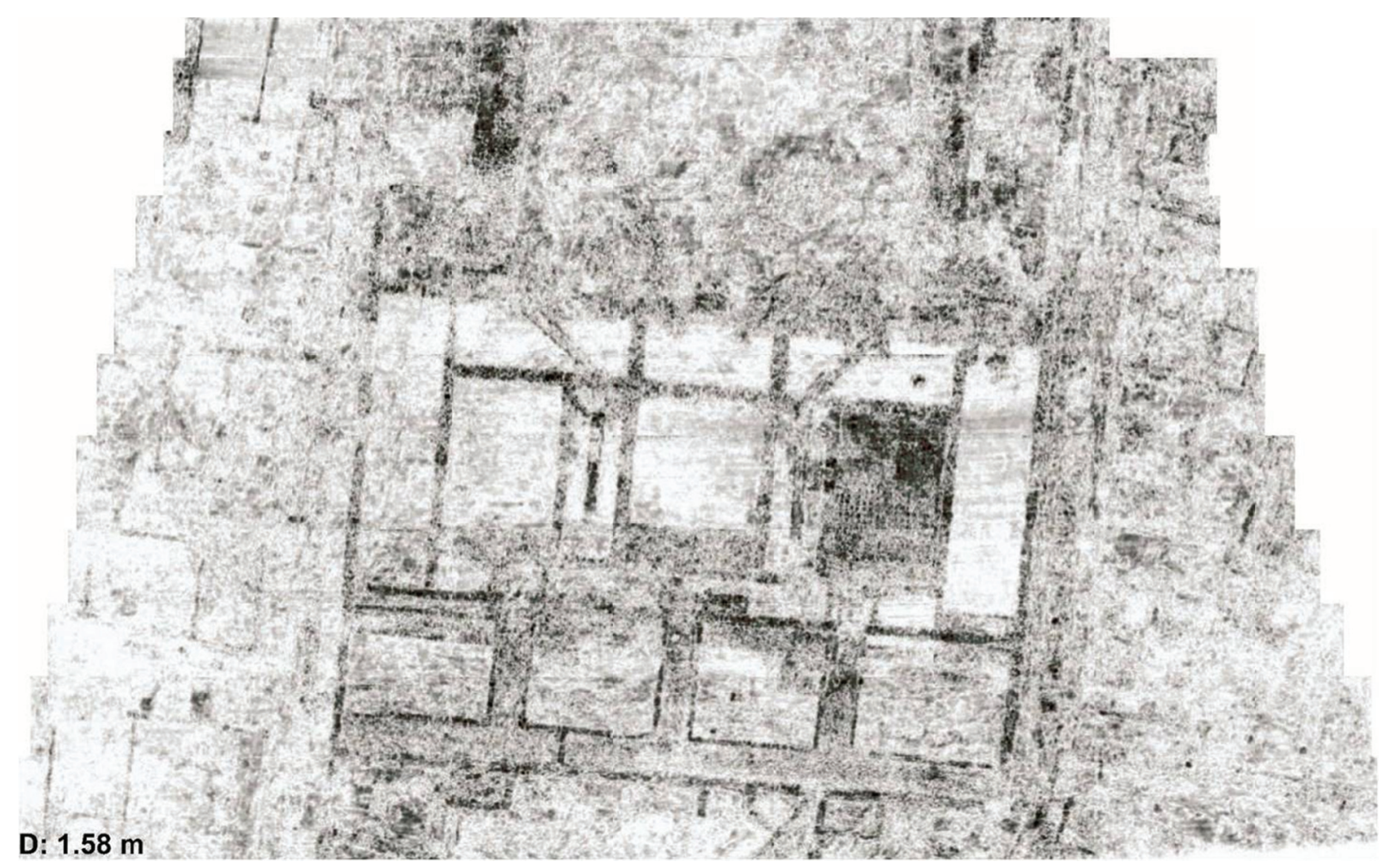

Figure 5. The 16-channel MALÅ Imaging Radar Array permits the efficient survey of up to three hectares per day in unprecedented resolution: this GPR depth-slice from approximately $1.58 \mathrm{~m}$ depth for the first time resolved the individual pillars (visible as rows of black dots) of the hypocaust

system in the easternmost room of the Forum building in the Roman town of Carnuntum, Austria (courtesy of MALA Geoscience AB).

3.2.3 Data processing and visualization of large-scale geophysical data: The new motorized multi-sensor devices and the combination of the micro-topography with geophysical survey data demand appropriate algorithms for optimized data interpolation and the implementation and application of improved data correction algorithms. Additionally, large-scale archaeological geophysical prospection surveys require novel data processing algorithms for the removal and suppression of disturbing noise in the data and unwanted side effects of the towing vehicles and multichannel arrays. Data acquired during motorized prospection surveys lacks regular sample spacing, which complicates the problem of data merging due to amplitude offsets caused by measurements conducted with different system orientations, on different days, times of the year, and changing weather and ground conditions.

A further important objective of the LBI ArchPro is therefore the optimization of the data processing and visualization routines through implementation of improved, and development of novel data processing and imaging algorithms. The key target will be the generation of data images of highest resolution and quality, that most realistically show the subsurface structures of interest, presented in a graphically suitable and easy perceivable style.

\subsection{Integrative archaeological data interpretation and spatiotemporal analysis}

The LBI ArchPro research programme produces new complex datasets of archaeological landscapes. These demand adequate data management and an integrated archaeological interpretation. Therefore, novel concepts of dynamic analysis including temporal relations and attributes have to be developed. The main challenge is the transformation of the acquired and processed complex physical prospection data into interpretative archaeological information that is accurate, readable and ready to use for other archaeologists.
The main platform for integrated archaeological interpretation will be a GIS-based archaeollogical information system, extended by appropriate, easy-to-use tools for dynamic visualization and spatial analysis for integrated archaeological interpretation, data archiving, data retrieval and long term maintenance.

\subsection{Case Studies}

Within the research programme, various geographical areas have been selected in order to provide different archaeological landscapes for distinct case studies. Here, all non-invasive, methods and techniques mentioned above will be combined, including remote sensing, geophysical prospection, Virtual Reality and dynamic GIS-based integrated archaeological interpretation. The proposed presentation will focus on these case-study areas and present the latest developments and results of the integrated prospection approach.

\section{OUTLOOK}

By bringing together national and international experts in the fields of high-tech archaeological prospection and computational science, the LBI ArchPro and its partners will drive an active research and development unit, establishing new standards and contributing at the highest levels to the field of international archaeological science. In the long-term perspective, the knowledge, hard- and software tools, as well as the scientific results produced by the LBI ArchPro will permit routine application of novel methodologies and techniques which will be of fundamental benefit to archaeological science and the investigation and protection of endangered cultural heritage. The aim of the LBI ArchPro initiative is to develop and apply cutting-edge technology and integrated interpretation approaches to illuminate archaeological heritage by visualising 
unique, formerly unknown, and otherwise invisible archaeological monuments and sites, which will be of great value to scientists as well as the general public alike. Providing scientists with new technological solutions, the development of novel archaeological concepts based on empirical data collected in great quality and quantity will be possible. Expanding the international LBI ArchPro case studies into large-scale applications, the work conducted within the research consortium will provide scientific access to GIS-based virtual and scalable archaeological data - from individual postholes to entire archaeological landscapes.

\section{ACKNOWLEDGEMENTS}

The authors wish to express their thanks to the team of the LBI ArchPro and its partners. The Ludwig Boltzmann Institute for Archaeological Prospection and Virtual Archaeology (http://archpro.lbg.ac.at) is based on an international cooperation of the Ludwig Boltzmann Society (A), the University of Vienna (A), the Vienna University of Technology (A), the Austrian Central Institute for Meteorology and Geodynamic (A), the office of the provincial government of Lower Austria (A), Airborne Technologies (A), the RomanGermanic Central Museum in Mainz (D), the Swedish Central National Heritage Board (S), the IBM VISTA laboratory at the University of Birmingham (GB) and the Norwegian Institute for Cultural Heritage Research (N).

\section{REFERENCES}

Becker H., 2009. Caesium-magnetometry for landscape archaeology. In: Campana S. and Piro S. (Eds.), Seeing the unseen - Geophysics and landscape archaeology, London 2009, 129-165.

Doneus, M., Briese, C., Studnicka, N., 2010. Analysis of FullWaveform ALS Data by Simultaneously Acquired TLS Data: Towards an Advanced DTM Generation in Wooded Areas. In: Wagner, W., Székely, B., 100 Years ISPRS, Advancing Remote Sensing Science. ISPRS Technical Commission VII Symposium, Vienna, Austria, July $5-7$, 2010. The International Archives of the Photogrammetry, Remote Sensing and Spatial Information Sciences, Vol. XXXVIII, Part 7B, 193198.

Doneus, M., Briese, C. 2011. Airborne Laser Scanning in Forested Areas - Potential and Limitations of an Archaeological Prospection Technique. In: Cowley D. C. (ed.) 2011, Remote Sensing for Archaeological Heritage Management, proceedings of an EAC Symposium, Reykjavik, Iceland, 25 -27 March 2010, EAC Occasional Paper No. 5, Archaeolingua.

Doneus M., Neubauer W., Verhoeven G., Briese C. 2011. Advancing archaeological airborne remote sensing. In: Drahor, M. G., Berge M.A.: Archaeological Prospection. 9th
International Conference on Archaeological Prospection. September 19-24, 2011 Izmir-Turkey, Archaeology and Art Publications, Istanbul 2011, 12-15.

Gaffney C. F. and Gater J., 2003. Revealing the buried past: geophysics for archaeologists. Tempus, Stroud.

Gaffney C., 2008. Detecting trends in the prediction of the buried past: a review of geophysical techniques in archaeology. Archaeometry 50, 2008, 313-336.

Goodman D., Nishimura Y., Hongo H. and Higashi N., 2006. Correcting for Topography and the Tilt of Ground-penetrating Radar Antennae. Archaeological Prospection 13, 2006, 159163.

Leckebusch J. 2005. Precision real-time positioning for fast geophysical prospection. Archaeological Prospection 12, 2005, 199-202.

Lehner, H., Briese, C., 2010. Radiometric calibration of FullWaveform Airborne Laser Scanning Data based on natural surfaces. In: Wagner, W., Székely, B., 100 Years ISPRS, Advancing Remote Sensing Science. ISPRS Technical Commission VII Symposium, Vienna, Austria, July 5 - 7, 2010. The International Archives of the Photogrammetry, Remote Sensing and Spatial Information Sciences, Vol. XXXVIII, Part 7B, 360-365.

Linford N., 2006. The application of geophysical methods to archaeological prospection. Reports on progress in Physics 69, 2006, 2205-57.

Neubauer W., 2001b. Images of the Invisible - Prospection methods for the documentation of threatened archaeological sites. Naturwissenschaften 88, 2001, 13-24.

Pfeifer N. and Briese C., 2007. Geometrical Aspects of Airborne and Terrestrial Laser Scanning. Keynote Lecture: ISPRS Workshop Laser Scanning 2007, Espoo, Finland. In: "IAPRS", XXXVI Part 3 / W52 (2007).

Scollar I., Tabbagh A., Hesse A. and Herzog I., 1990. Archaeological Prospecting and Remote Sensing. CUP, Cambridge.

Trinks I., Johansson B., Gustafsson J., Emilsson J., Friborg J., Gustafsson C., Nissen J. and Hinterleitner A., 2010. Efficient, larger-scale archaeological prospection using a true threedimensional ground penetrating radar array system. Archaeological Prospection 17(3), 175-186.

Verhoeven G., 2008. Imaging the Invisible - Using modified Digital Cameras for Straightforward and Low-Cost Archaeological Near-InfraRed Photography. Journal of Archaeological Science 35, 2008, 3087-3100. 